Viktorija Osolnik Kunc

DOI: $10.4312 /$ vestnik.7.307-311

Univerza v Ljubljani

Filozofska fakulteta

viktorija.osolnik-kunc@guest.arnes.si

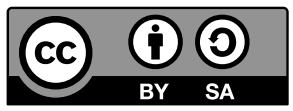

\title{
POROČILO Z XX. SVETOVNEGA KONGRESA FIT (2014)
}

Pod geslom Človek proti stroju (Man vs. Machine) je med 4. in 6. avgustom 2014 v Berlinu potekal 20. Svetovni kongres Mednarodne zveze prevajalcev FIT (Fédération Internationale des Traducteurs $)^{1}$. FIT vsaka tri leta v različnih državah po svetu organizira kongrese, ki so namenjeni žgočim temam v prevodoslovju, novim tehnologijam, izmenjavi mnenj strokovnjakov in seveda medsebojnemu druženju.

Zveza je bila ustanovljena leta 1953 v Parizu in je na XX. svetovnem kongresu praznovala 60. obletnico obstoja. Danes ima regionalne centre v Evropi, Latinski Ameriki in Severni Ameriki.

Letošnji organizator kongresa je bilo nemško Zvezno združenje tolmačev in prevajalcev $B D \ddot{U}$ (Bundesverband für Dolmetscher und Übersetzer). Kongresa se je udeležilo preko 1.600 obiskovalcev iz 70 držav. Prijavljenih je bilo skoraj 390 prispevkov - od predavanj, delavnic do okroglih miz in posterjev -, ki so sočasno potekali v dvanajstih sekcijah.

Generalna direktorica Unesca IRINA BoKova je opozorila na pomembno vlogo, ki jo imajo prevajalci, saj je prevajanje eno od načel, ki ohranjajo pri življenju ustvarjalno različnost in nas skozi stike s tujimi jeziki bogatijo. Ohranjanje kulturne različnosti podpira Unesco tudi s svetovnim bibliografskim registrom prevodov Index Translationum, utemeljenim leta 1932, ki hrani preko dva milijona prevodov z različnih področij.

Predsednica FIT-a, MARION BoErs iz Republike Južne Afrike, je izpostavila, da sta prevajalska in tolmaška stroka $v$ zadnjih šestdesetih letih zaradi globalizacije in razvijajoče se družbe znanja v svetu pridobili na pomembnosti in prepoznavnosti. Organizatorji so zato v ospredje kongresa postavili človeka $\mathrm{v}$ znamenju sodobnih tehnologij.

Sporočilo kongresa je bilo jasno. Prevajanja brez podpore računalniških tehnologij si danes ni več mogoče zamisliti. Veliko pozornosti je bilo namenjeno računalniško podprtemu prevajanju oz. prevajalskim orodjem (t. i. CAT Tools-om), strojnim prevajalnikom, procesu lokalizacije, procesom zagotavljanja kakovosti v skladu s standardom DIN EN $15038^{2}$ in spletnim prevajalskim orodjem. Predstavljene so bile tudi sodobne metode dela prevajalcev, kot so delo v oblaku, delo s pomočjo pametnih telefonov ali tablic, delo ob uporabi družabnih omrežij, in orodja za upravljanje s terminološkimi bazami. Izpostavljeni

1 Za več informacij glej spletno stran www.fit2014.org.

2 Evropski standard za ponudnike prevajalskih storitev DIN EN 15038 velja od leta 2006. Pred tem je bil v veljavi standard za prevajanje DIN 2345. 
so bili družbena odgovornost vseh nas do prevajalcev in tolmačev, delovanje trga dela in vloga strokovnih društev, ki so za stroko zelo pomembna.

Ob zaključku tridnevnega dogodka so udeleženci kongresa sprejeli resolucijo, s katero želijo opozoriti na vse tiste kolege, ki svoje delo opravljajo na kriznih območjih. FIT poziva vse vlade in mednarodno skupnost, da zaščitijo lokalne prevajalce in tolmače na kriznih območjih, da spoštujejo osebno etiko, poklicne zahteve in nepristranskost prevajalcev in tolmačev pri njihovem delu, in da se zavzemajo za mednarodni dokument za zaščito prevajalcev in tolmačev na kriznih območjih med in po zaključku njihovega dela.

6. člen Evropske konvencije o varstvu človekovih pravic in temeljnih svoboščin in 47. člen Listine Evropske unije o temeljnih pravicah kot tudi Direktiva 64/2010/EU sicer zagotavljajo pravico do obrambe za vse udeležence, ki se znajdejo v kazenskih postopkih.

Na kongresu so bili predstavljeni tudi prispevki o diplomaciji in jeziku, o tolmačenju govorice gluhonemih, o delu za potrebe skupnosti (angl. community interpreting), o sodnem tolmačenju in pravnem prevajanju, kot tudi o prevajanju listin kot samostojni prevajalski panogi.

$\mathrm{V}$ delu, namenjenem pravnemu prevajanju in sodnemu tolmačenju, je bilo več zanimivih prispevkov. Raziskovalki in sodni tolmački IsABELle THORMANN (Nemčija) in RADEGUNDIS STOLze (Nemčija) sta na primer v ločenih delavnicah predstavili, na kaj vse moramo biti pozorni pri prevajanju zasebnih in javnih listin, ki so v prevodu opremljene z izjavo prevajalca o skladnosti prevoda z izvirnikom (t.i. overjeni prevod). Z razliko od slovenskega sodnega tolmača to delo v nemškem govornem okolju opravlja (stalno zapriseženi) Urkundenübersetzer ${ }^{3}$ (prevajalec listin). Način nagrajevanja je, podobno kot v slovenski zakonodaji, zapisan v nemškem področnem Zakonu o nagradah in nadomestilih v sodstvu JVEG (Justizvergütungs- und -entschädigungsgesetz). Tolmači so plačani na podlagi urne postavke, prevajalci pa po vrstici prevoda v ciljnem jeziku. ${ }^{4}$

Znane hamburške smernice ${ }^{5}$, ki jih marsikateri prevajalec kljub zelo koristnim nasvetom, žal še vedno preslabo pozna, sta dopolnili še z nekaterimi nasveti. STOLZEJEvA na primer svetuje, naj bi prevajalec morebitne opombe $\mathrm{k}$ besedilu raje vključeval $\mathrm{v}$ besedilo $\mathrm{z}$ »op. prev.«. Za opombe ob koncu strani pa naj bi se odločil takrat, ko bi bilo to zaradi postavitve besedila (layout) ugodneje. Opozarja tudi, naj bi koleke, štampiljke in žige oz. pečate v prevodu na kratko opisali (npr. rdeča štampiljka + prevod vsebine), medtem ko bi vsebinski del pečatov (uradni okrogli znak organa) prevajali le, če bi obstajal dvom med identiteto izdajatelja dokumenta in uradnim znakom.

Thormannova pa je poudarila, da je treba s prevodom listine v ciljnem jeziku po vsebini in funkciji doseči enak učinek, kot ga ima izvirnik.

\footnotetext{
3 Zapriseženi Urkundenübersetzer v Nemčiji ni hkrati imenovan za tolmačenje v sodnih postopkih in pred uradnimi institucijami, zato tudi nima naziva sodnega tolmača (nem. Gerichtsdolmetscher).

4 Po nemškem zakonu JVEG znaša urna postavka tolmačenja 70 EUR, vrstica prevoda (55 znakov brez presledkov praviloma v ciljnem jeziku) pa 1,55 EUR. Za podrobnosti glej 8. - 14. člen zakona.

5 Smernice (nem. Merkblatt für die Anfertigung von beglaubigten Übersetzungen) je izdal Urad za notranje zadeve Svobodnega in hanzeatskega mesta Hamburg, prvič leta 2002 in v dopolnjeni različici leta 2010.
} 
Doktorska kandidatka MARTA SKOREK (Poljska) je razpravljala o večnem vprašanju o boljšem pravnem prevodu. Primerjala je jurilinguista ${ }^{6}$, pravnika lingvista in pravnega prevajalca v dveh večjezičnih skupnostih, v Kanadi in v Evropski uniji. Optimalno rešitev vidi v specializiranem študiju pravnih, jezikovnih in prevajalskih predmetov.

Natalia Sigareva (Rusija) s Pedagoške univerze Herzen je govorila o tolmačenju za potrebe skupnosti v Rusiji. Predstavila je izsledke raziskave, v kateri je skupina raziskovalcev primerjala predpise s stanjem v praksi na področju tolmačenja, prevajanja in pomoči v komunikaciji v javnih službah v St. Peterburgu. Mesto naj bi po zagotovilih sogovornice veljalo za reprezentativno za celotno Rusijo. Ruska federacija se po razpadu Sovjetske zveze sooča z velikim številom migrantov, beguncev in azilantov ${ }^{7}$, zato potreba po tolmačenju - v zdravniških ordinacijah in med zdravljenjem, na policijskih postajah, v šoli ali prosilcem za azil - narašča. V Rusiji zato v tem vidijo izziv za razvoj področja tolmačenja za javne institucije, saj podobno kot v Sloveniji tudi v Rusiji ne poznajo posebnega šolanja za delo t.i. community interpretinga. V Rusiji to delo pogosto opravljajo osebe brez ustrezne izobrazbe ali pa družinski člani, največkrat otroci, ki se učijo ruskega jezika v šoli. V preteklosti je bilo to delo v Rusiji tudi razumljeno kot manj vredno od sodnega ali konferenčnega tolmačenja ${ }^{8}$.

Kirsty HeImerl-Moggan (Velika Britanija) se je ukvarjala s prav posebno temo, in sicer z razseljenimi osebami z vojnih območij, ki so postale uspešni tolmači. Pripovedovala je o izkušnjah, ki jih ima kot predavateljica tolmačenja za potrebe skupnosti (poznano pod mnogimi imeni, tudi pod imenom public service interpreting). Pogosto je poučevala študente $\mathrm{z}$ aktualnih oz. nekdanjih vojnih območij, kot so nekdanja Jugoslavija, Irak in Afganistan. Nekateri od njih so že v matični državi delali kot tolmači na kriznem območju ali pa so se po begu v drugo državo odločili za študij konferenčnega tolmačenja oz. tolmačenja za potrebe skupnosti. Pogost razlog, da so se odločili postati tolmači, je bil, da so morali zapustiti svoje družine v matični državi. Tisti, ki so v tujo deželo prišli kot sirote, so preko vloge tolmača videli možnost povezovanja z matično državo. Nekateri so preko dela tolmača laže prebolevali travme iz vojnega obdobja, drugi spet pa so delo opravljali, ker je bilo to edino, kar so znali. Zanimivo je tudi, da so mnogi zelo hitro usvojili tolmaške sposobnosti, medtem ko hkrati niso bili usposobljeni za pisno prevajanje, saj je bilo njihovo jezikovno znanje $\mathrm{v}$ pisani besedi bistveno slabše od znanja $\mathrm{v}$ govorjeni besedi.

Joanna Miler-Cassino in Danuta KierzKowsKa sta predstavili Poljski svet stalno zapriseženih prevajalcev in strokovnih prevajalcev TEPIS. Na Poljskem seže tradicija stalno

6 V Kanadi poznajo jurilinguista. To je oseba, ki svetuje v zvezi s terminologijo, sintakso, frazeologijo, pravno stilistiko, še posebej pri zakonskem jeziku, in ki skrbi za skladnost angleške in francoske različice zakonskih in podzakonskih aktov. SкоRек (2014: 560) citira PoIRIER (2010) ki pravi, da je večina jurilinguistov poleg študija prevajanja opravila dodatno izobraževanje s pravnih področij oz. ima celo diplomo iz prava. Pravniki v Kanadi vseeno tako kot njihovi kolegi v Evropi vztrajajo, da mora imeti jurilinguist pravno izobrazbo.

7 Šlo naj bi za osebe iz osrednjih azijskih republik nekdanje Sovjetske zveze.

8 SigareVA navaja, da sodno tolmačenje v Rusiji ni certificirano oz. da tisti, ki nastopajo $\mathrm{v}$ vlogi sodnih tolmačev za to delo nimajo potrdila. Po trenutni zakonodaji lahko v vlogi sodnega tolmača nastopa vsaka polnoletna oseba, ki izkaže jezikovne kompetence v tujem jeziku. 
zapriseženih prevajalcev daleč v začetek 20. stoletja 9 . Pravilnik, ki ga je izdal minister za pravosodje o nagradah za priče, izvedence in prevajalce v kazenskih zadevah 7. avgusta 1920, je temeljil na pravilniku avstrijskega ministra za pravosodje, ki je bil sprejet 17. septembra 1897, v obdobju delitve Poljske. Že leta 1928 so v pravilnik vnesli določilo o izobrazbi prevajalca in področjih specializacije. Sodišča so v civilnih in kazenskih zadevah lahko izbirala le med stalno zapriseženimi prevajalci, katerih imena so bila letno objavljena v uradnem listu. Leta 2004 je bil na Poljskem sprejet Zakon o poklicu stalno zapriseženega prevajalca, v katerem je bil uveden naziv »stalno zapriseženi prevajalec« (polj. ttumacz przysięgły, angl. sworn translator), ki v poljski zakonodaji predstavlja osebo, ki prevaja (pisano besedo) in tolmači (govorjeno besedo). Ta v poljski javnosti uživa velik ugled, zlasti ker je izobraževanje za pripravo na izpit dolgotrajno in ker mu naziv podeljujejo predsedujoči sodnik vojvodskega upravnega sodišča ali poljski minister za pravosodje. Za pripravo na izpit za pravnega prevajalca in tolmača lahko kandidati opravljajo izobraževanje, ki ga od leta 1998 ponuja Institut za uporabno jezikoslovje Univerze v Varšavi v sodelovanju s TEPISom. ${ }^{10}$ Program obsega skupno 360 ur in se osredotoča na tehnike prevajanja in tolmačenja, osnove poljskega prava, poljsko pravno stilistiko, diskurzivno analizo in metodologijo pravnega prevajanja in tolmačenja. Izobraževanje ponujajo za jezikovne kombinacije poljščina in angleščina, nemščina, francoščina, italijanščina, ruščina, španščina ali arabščina. ${ }^{11}$

Iz Slovenije se je kongresa udeležilo Združenje stalnih sodnih tolmačev in pravnih prevajalcev Slovenije $^{12}$, ki ga je zastopala njegova predsednica VIKTORIJA OsolniK KunC. Združenje se je z omenjeno udeležbo prvič predstavilo tuji strokovni javnosti. V sekciji Legal forum je predsednica predstavila profil in delo sodnih tolmačev v Sloveniji. Opozorila je na pojmovno terminološko raznovrstnost na področju tolmačenja in prevajanja za potrebe sodišč in uradnih institucij v Sloveniji in v tujini. Poleg dela združenja pa je govorila tudi o delu in vlogi Ministrstva za pravosodje in Centra za izobraževanje v pravosodju Republike Slovenije pri vseživljenjskem izobraževanju sodnih tolmačev v Sloveniji. ${ }^{13}$

9 Za primerjavo - prva slovenska uredba o sodnih tolmačih je bila objavljena 16.2.1949 v UL LRS 7-30/49. Za več glej opombo 13.

10 Ne glede na usposobljenost oz. na izobrazbo je uspešnost pri izpitu za pravnega prevajalca in tolmača na letni ravni le med 25 in 35 odstotna.

11 Žal se na Poljskem standard za imenovane pravne prevajalce in tolmače zaradi ambiciozne reforme države za lažji dostop do reguliranih poklicev poslabšuje. Poljska je leta 2013 izvedla prvi del reforme, s katero je liberalizirala dostop do 50 poklicev, vključno s pravniki, notarji, nepremičninskimi posredniki in taksisti. Danes zadostuje, da ima kandidat za pravnega prevajalca in tolmača prvostopenjsko izobrazbo (Bachelor's degree) in ne več drugostopenjsko (Master's degree oz. poljski magister (mgr)), kot je to zahteval zakon iz leta 2004. Prav tako so nagrade po pridobljenem nazivu zelo slabe. Za eno stran overjenega prevoda (1125 znakov s presledki v ciljnem jeziku) prejmejo 5,50 EUR neto in za uro tolmačenja 9,40 EUR neto.

12 Združenje je bilo ustanovljeno leta 2012 s sedežem v Logatcu. Gre za prvo specializirano društvo, ki združuje sodne tolmače in pravne prevajalce, medtem ko druga društva sodne tolmače združujejo le v obliki sekcij. Združenje danes šteje preko 80 članov, kar je impresiven podatek glede na dejstvo, da je število vseh imenovanih sodnih tolmačev v Republiki Sloveniji po podatkih iz marca 2015 skupno 662, medtem ko je vseh vpisanih sodnih tolmačev po posameznih jezikih skupno 882 .

13 Strokovni prispevek avtorice: OSOLNIK Kunc, Viktorija (2014) Der Gerichtsdolmetscher. Über Profil und Arbeit in Slowenien. Baur, Wolfram in dr. (ur.), Man vs. Machine?. 2. knjiga. Berlin: BDÜ Fachverlag, $799-807$. 
Uveljavljenih splošnih in specializiranih mednarodnih dogodkov s področja prevajanja in tolmačenja se slovenska prevajalska in tolmaška stroka žal udeležuje v še precej skromnem številu. Naj bo ta kratka predstavitev kongresnega dogajanja ne le poročilo, temveč tudi povabilo in vzpodbuda za vse, da bi se tovrstnih ključnih mednarodnih dogodkov udeležili v večjem številu kot doslej.

XXI. kongres FIT-a bo leta 2017 v Brisbaneu, v Avstraliji. Se vidimo tam! 